Supplement of Biogeosciences, 12, 3131-3140, 2015

http://www.biogeosciences.net/12/3131/2015/

doi:10.5194/bg-12-3131-2015-supplement

(C) Author(s) 2015. CC Attribution 3.0 License.

(c) (i)

Supplement of

\title{
Atmospheric water-soluble organic nitrogen (WSON) over marine environments: a global perspective
}

K. Violaki et al.

Correspondence to: N. Mihalopoulos (mihalo@chemistry.uoc.gr)

The copyright of individual parts of the supplement might differ from the CC-BY 3.0 licence. 


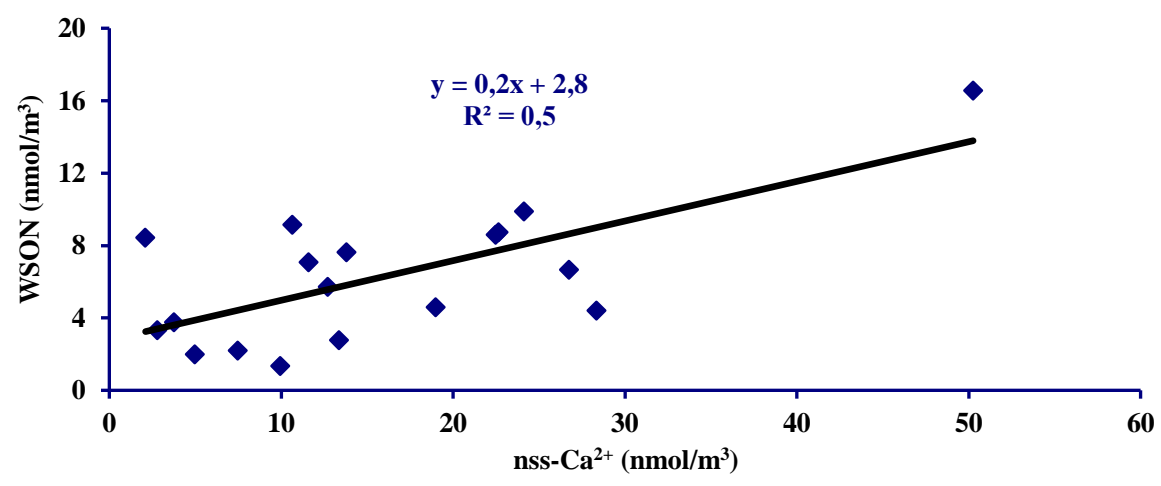

Fig.S1: Correlation between WSON \& nss-Ca ${ }^{2+}$ in coarse mode particles (Da $\left.2 \mu \mathrm{m}\right)$ during Meteor cruise $(\mathrm{N}=18)$.

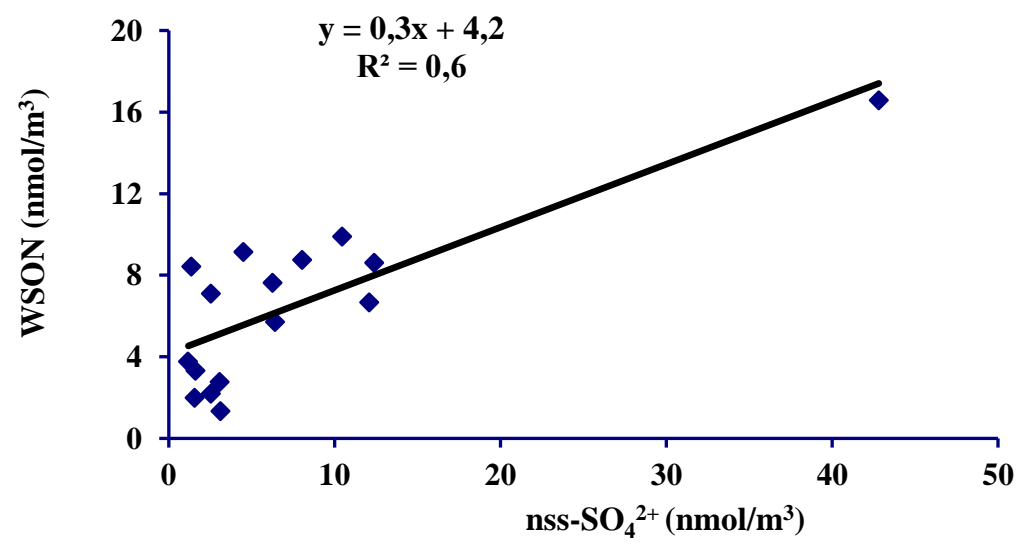

Fig.S2: Correlation between WSON \& nss-Sulfate in coarse mode particles ( $\mathrm{Da}>2 \mu \mathrm{m})$ during Meteor cruise $(\mathrm{N}=18)$. 


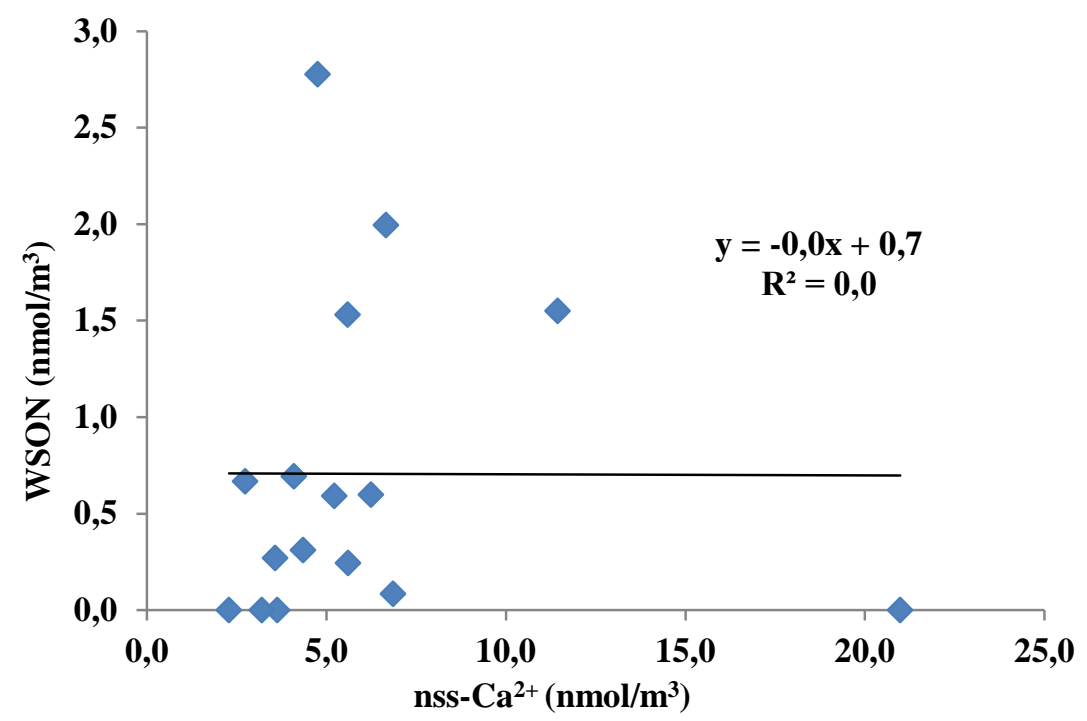

Fig.S3: Correlation between WSON \& nss-Calcium in fine mode particles $(\mathrm{Da}<2 \mu \mathrm{m})$ during Meteor cruise.

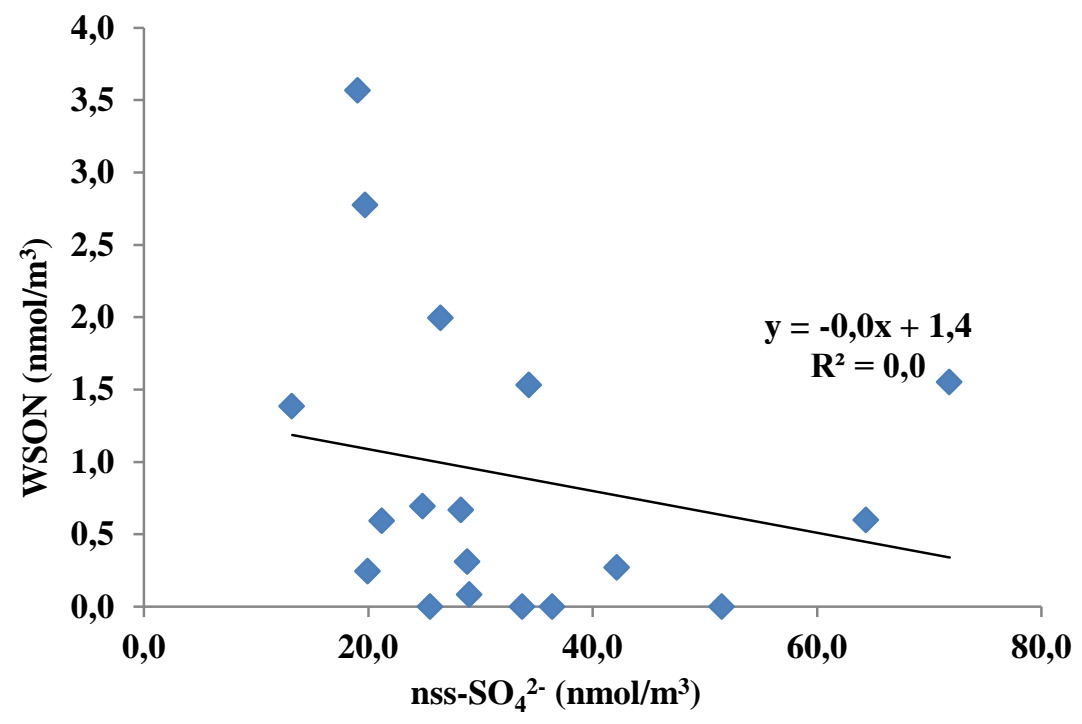

Fig.S4: Correlation between WSON \& nss-Sulfate in fine mode particles ( $\mathrm{Da}<2 \mu \mathrm{m})$ during Meteor cruise. 


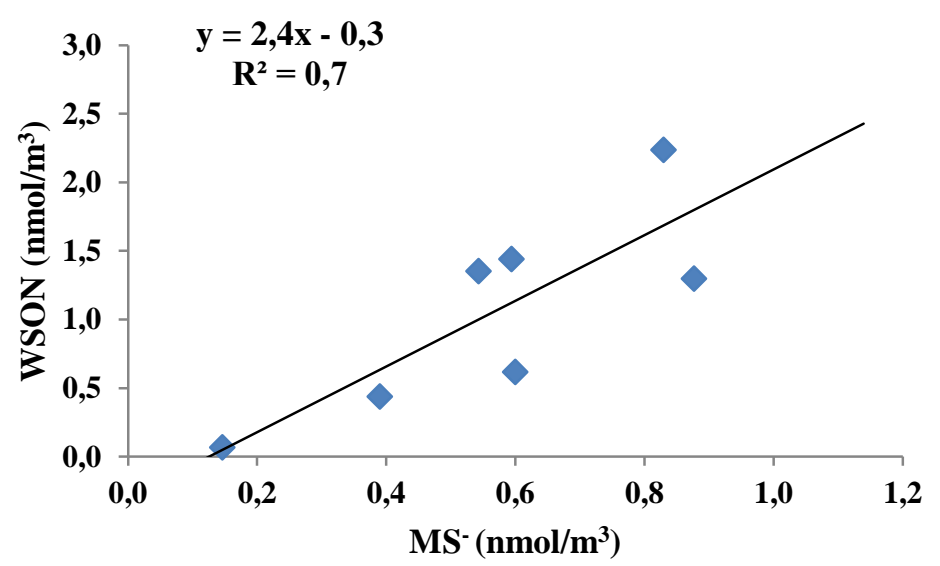

Fig.S5: Correlation between WSON \& $\mathrm{MS}^{-}$in fine mode particles in Amsterdam Island (N=7).

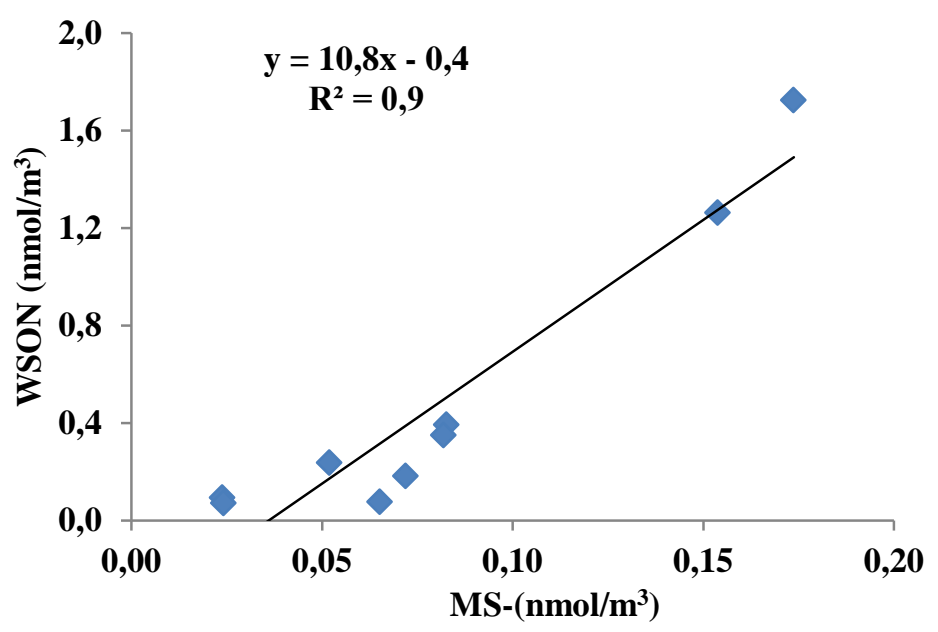

Fig.S6: Correlation between WSON \& $\mathrm{MS}^{-}$in coarse mode particles in Amsterdam Island $(\mathrm{N}=9)$. 